\title{
Identification of Markers Associated with Birth Weight in Boer Goat
}

\author{
Jamli S, Shanmugavelu S \\ Animal Science Research Centre, Malaysian Agricultural Research and Development Institute (MARDI) \\ MARDI H, Persiaran MARDI-UPM, Serdang 43400, Selangor, Malaysia \\ saadiahj@mardi.gov.my
}

\begin{abstract}
Genetic improvement of breeding depends on selective breeding of superior phenotypes. In order to increase accuracy of breeding and selection for efficient production systems, current trend is towards applying molecular markers. The purpose of the study was to identify markers associated with birth weight in Boer goats using 50k single nucleotide polymorphism (SNP) chip. A total of 657 Boer goats were selected based on the availability of birth weight data from a commercial farm. Individuals were genotyped using 50k SNP chip from Illumina using Illumina Genome Analyzer IIx. A genome wide association analysis using a mixed model was carried out and resulted in 32 detected markers for birth weight. In previous genotyping study done on the same population of goat using 20k custom-designed SNP chip resulted in 14 markers for birth weight. However, markers identified should be verified in an independent population before being applied in a Marker Assisted Selection (MAS) program. Further consideration should be on socioeconomic factors as well as their sustainability in biodiverse environments.
\end{abstract}

Key Words: Molecular Markers, 50k SNP Chip, Boer Goat

\section{INTRODUCTION}

Genetic improvement of breeding depends on selective breeding of superior phenotypes. In order to increase accuracy of breeding and selection for efficient production systems, current trends is towards applying molecular markers. Molecular markers have been explored to evaluate the livestock performance for the purpose of genetic improvement (Montaldo \& Meza-Herrera 1998; Dekkers 2004) as well for genetic diversity (Groeneveld 2010).

Currently, SNP panel are widely used to identify markers for various traits in livestock such as body weight (Esmailizadeh 2014; Jung et al. 2014; Somavilla 2014), reproductive (Tart et al. 2013; Sasaki et al. 2015; Farah et al. 2016; Ortega et al. 2016) and carcass traits (Onogi et al. 2015; Skok et al. 2016). SNP panel are also used in genetic diversity studies (Nicoloso et al. 2015; Manunza et al. 2016; Visser et al. 2016).

Based on these findings, there is potential of using markers in breeding and selection programmes. Birth weight is one of the traits of interest. Birth weight is an economically important trait and an important indicator of potential growth of livestock species. Birth weight has a direct effect on weights at subsequent ages, growth rate, rate of maturing and carcass characteristics (Greenwood et al. 1998). Low birth weight is normally associated with neonatal mortality (Morel et al. 2008). Weight is controlled by multigenes and environmental factors. Identification of markers associated with birth weight is important for genetic improvement program in a breeding population. The purpose of the study was to identify markers associated with birth weight in Boer goats using 50k single nucleotide polymorphism (SNP) chip. 


\section{MATERIAL AND METHODS}

\section{Biological samples and genotyping}

A total of 657 Boer goats were selected based on the availability of birth weight data from a commercial farm at Negeri Sembilan, Malaysia. The parental stock of these Boer goats were imported from Australia.

DNA samples were extracted using a Promega Wizard Genomic DNA Purification System. Individuals were genotyped using the Goat SNP50 Beadchip (Illumina Inc., San Diego, CA) developed by the International Goat Genome Consortium (Tosser-Klopp et al. 2014). Genotyping was done at DNA Landmarks Inc. using Illumina Genome Analyzer IIx.

\section{Whole genome association (WGA) and SNP Selection}

To maximize the information from 50k genotyping, the samples with low call rate $(<90 \%)$ and without phenotype data were excluded. Samples with the pedigree information were included in the 50k typing.

To select a panel of significant SNPs, those SNPs were selected based on their own $p$ value but also the P-value of the nearby SNPs. The regions that showed multiple SNPs with significant association were considered as promising regions.The most significant SNP was selected from such peaks. The minimum $\mathrm{P}$-value is set as $\mathrm{P}<0.01$ for SNP selection.

The statistical analysis was performed using ASREML by 2-step Mixed model (Aulchenko et al. 2007). The model for the body weight was: BW = Sex + Type of birth + Polygenic effect and SNP effect. In order to estimate polygenic effect, the relationship matrix was calculated using genotypes rather than pedigree due to some pedigree errors in the dataset. Sex and type of birth were estimated as fixed effects for birth weight. SNPs were selected based on the P-value of individuals SNPs as well as P-value of the nearby SNPs.

\section{RESULTS AND DISCUSSION}

Chromosomes and SNPs position from this study are shown on Manhattan plots in Figure 1. Different colors in the figures are used to separate different chromosome based on cattle genome. The position is also based on cattle chromosome. Each dot in the figure means a SNP. The SNP with high $-\log 10$ (P-value) indicate higher association with the trait. The $\log 10(\mathrm{P}$-value $)=3$ is equivalent to $\mathrm{P}=0.001$.

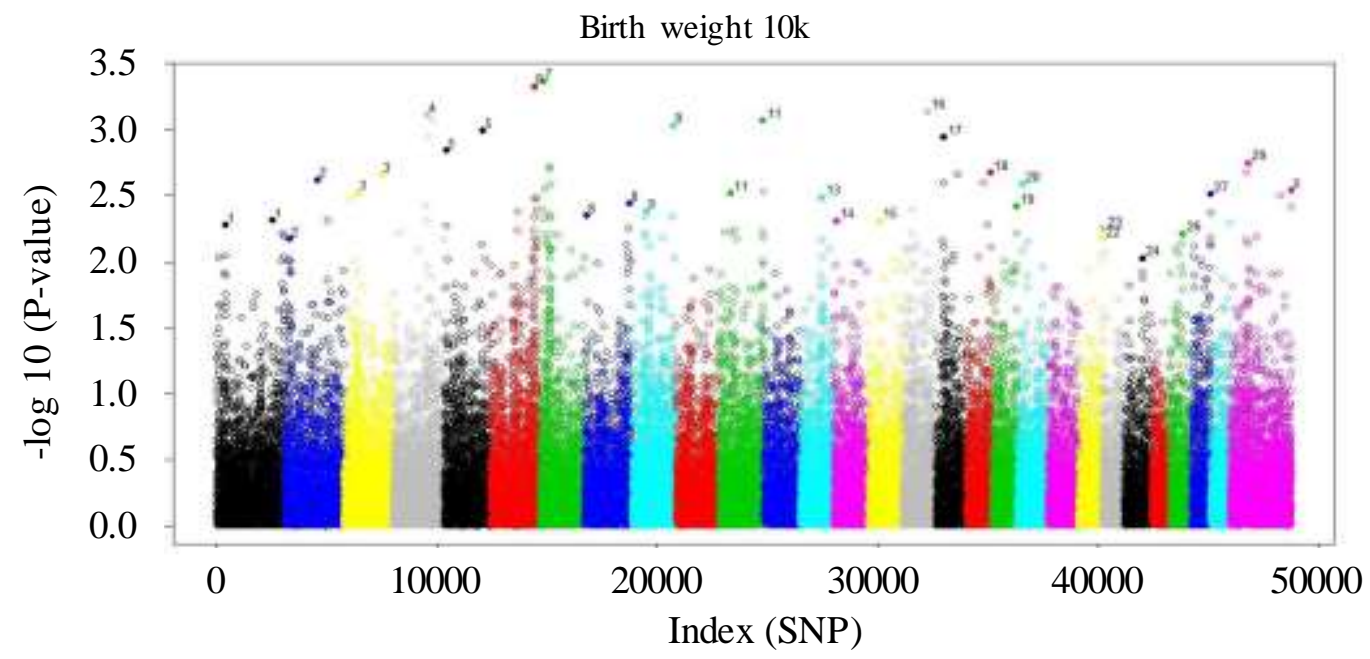

Figure 1. Manhattan plots of SNP associated with birth weight using 50k SNP chip 
The P-value for SNPs selected is shown in Table 1. The minimum P-value considered for SNPs selection in this study was $\mathrm{P}<0.01$. The study identified 32 markers associated with birth weight from the Boer goat population (Table 1).

Table 1. Description of SNPs associated with birth weight in Boer goats

\begin{tabular}{|c|c|c|c|}
\hline SNP name & Position & P-value & No. of animals \\
\hline snp2671-scaffold1077-260243 & 19909684 & 0.005297 & 657 \\
\hline snp11813-scaffold1438-715481 & 129502496 & 0.004868 & 657 \\
\hline snp32307-scaffold367-263826 & 9767203 & 0.006697 & 657 \\
\hline snp50955-scaffold739-2803010 & 74046302 & 0.002391 & 657 \\
\hline snp37581-scaffold460-60946 & 33758693 & 0.002999 & 657 \\
\hline snp44026-scaffold595-5741464 & 93639804 & 0.002201 & 656 \\
\hline snp38964-scaffold494-3410708 & 80093565 & 0.000769 & 644 \\
\hline snp15225-scaffold1622-357391 & 5648416 & 0.001430 & 654 \\
\hline snp56986-scaffold903-353290 & 99263534 & 0.001016 & 657 \\
\hline snp25700-scaffold2643-789862 & 105389938 & 0.000470 & 657 \\
\hline snp22606-scaffold224-142058 & 8647570 & 0.000431 & 657 \\
\hline snp33318-scaffold391-2347591 & 4580242 & 0.004488 & 657 \\
\hline snp31895-scaffold356-4322178 & 106432736 & 0.003616 & 656 \\
\hline snp474-scaffold1011-1799744 & 33253406 & 0.004124 & 656 \\
\hline snp36799-scaffold447-297097 & 98382724 & 0.000933 & 657 \\
\hline snp9777-scaffold135-3200308 & 26279972 & 0.003015 & 657 \\
\hline snp17416-scaffold1803-76969 & 103665273 & 0.000856 & 655 \\
\hline snp13092-scaffold150-5061100 & 53167884 & 0.003260 & 657 \\
\hline snp21427-scaffold209-942795 & 7015359 & 0.004899 & 657 \\
\hline snp8602-scaffold131-1092240 & 61141555 & 0.000731 & 657 \\
\hline snp21169-scaffold207-2673559 & 18229249 & 0.001137 & 656 \\
\hline snp26870-scaffold283-439363 & 57378759 & 0.002129 & 657 \\
\hline snp41374-scaffold537-4310995 & 61758779 & 0.003800 & 657 \\
\hline snp14677-scaffold1591-1036604 & 11253247 & 0.002574 & 657 \\
\hline snp48747-scaffold692-580888 & 2654510 & 0.005606 & 657 \\
\hline snp22924-scaffold229-76929 & 44318631 & 0.003064 & 657 \\
\hline snp17566-scaffold182-238289 & 46847552 & 0.001783 & 657 \\
\hline snp54569-scaffold833-1768789 & 40801388 & 0.009374 & 657 \\
\hline snp31701-scaffold353-108154 & 30725050 & 0.006161 & 657 \\
\hline snp52571-scaffold783-10947 & 147516206 & 0.002885 & 657 \\
\hline snp4850-scaffold1162-146734 & 27736297 & 0.004901 & 657 \\
\hline snp56008-scaffold870-892566 & 60050800 & 0.006743 & 649 \\
\hline
\end{tabular}

\section{Discussion}

A genome wide analysis using 50k SNP panel resulted in 32 detected markers. In previous genotyping study done on the same population of goat using $20 \mathrm{k}$ custom- 
designed SNP chip resulted in 14 markers for birth weight (Saadiah et al. 2014). The chromosomal regions of SNPs selected from 20k do not completely overlapped with the ones selected from 50k. This indicate the challenges in identifying markers that control traits. Various factors have to be taken into consideration in order for the markers to be accurately utilised in breeding programme. In a study done by Brito et al. (2015) on characterization of linkage disequilibrium indicate that genome selection could be implemented within breed for a large training population but some breeds will require a denser panel. Multi-breed genomic evaluation require a denser panel as well (Brito et al. 2015).

Application of these markers in a biodiversed environment and geographical location requires further consideration as several studies indicate huge genetic diversity within different goat population and geography. Different pattern of diversity displayed in different goat population such as genetic drift in Spanish (Manunza et al. 2016) and Italian goats (Nicoloso et al. 2015); lack of gene flow (Nicoloso et al. 2015) and admixture with other goat breed (Manunza et al. 2016; Visser et al. 2016). Geographical locations cause genetic distiction between the population. Furthermore, for purebred population, inbreeding depression have impact on economic income of breeders (Leroy 2014). It is expected that the genetic background will affect different pattern of genome wide association of various traits.

\section{CONCLUSION}

The results give more insight into the trait of interest for breeding animals. More denser SNP panel such as 50k chip resulted to more markers generated as compared to less dense SNP panel. The study contribute to the understanding of genomic variability in relation to the birth weight in locally adapted Boer goat. However, markers identified should be verified in an independent population before application in a Marker Assisted Selection program (MAS) program. Further consideration should also be given to socioeconomic factors as well as sustainability in a biodiverse environment.

\section{REFERENCES}

Aulchenko YS, De Koning DJ, Haley C. 2007. Genome wide rapid association using mixed model and regression: A fast and simple method for genome wide pedigree-based quantitative trait loci association analysis. Genetics. 177:577-585.

Brito LF, Jafarikia M, Grossi DA, Kijas JW, Porto-Neto LR, Ventura RV, Salgorzaei M, Chenkel FS. 2015. Characterization of linkage disequilibrium, consistency of gametic phase and admixture in Australian and Canadian goats. BMC Genetics. DOI: 10.1186/s12863-015-0220-1.

Dekkers JCM. 2004. Commercial application of marker- and gene-assisted selection in livestock: Strategies and lessons. J Anim Sci. 82(E Suppl.):E313-E328.

Esmailizadeh AK. 2014. Genome-scan analysis for genetic mapping of quantitative trait loci underlying birth weight and onset of puberty in doe kids (Capra hircus) Anim Genet. 45:849854.

Farah MM, Swan AA, Fortes MRS, Fonseca R, Moore SS, Kelly MJ. 2016. Accuracy of genomic selection for age at puberty in a multi-breed population of tropically adapted beef cattle. Anim Genet. 47:3-11.

Greenwood PL, Hunt AS, Hermanson JW, Bell AW. 1998. Effects of birth weight and postnatal nutrition on neonatal sheep: I. Body growth and composition, and some aspects of energetic efficiency. J Anim Sci. 76:2354-2367.

Groeneveld LF, Lenstra J, Eding H, Toro MA, Scherf B, Pilling D, Negrini R, Finlay EK, Jianlin H, Groeneveld E, Weigend S, The GLOBALDIV Consortium. 2010. Genetic diversity in farm animals-a review. Anim Genet. 41 (Suppl. 1):6-31. 
Jung EJ, Park HB, Lee JB, Yoo CK, Kim BM, Kim HI, Kim BW, Lim HT. 2014. Genome-wide association analysis identifies quantitative trait loci for growth in a Landrace purebred population. Anim Genet. 45:442-444.

Leroy G. 2014. Inbreeding depression in livestock species: review and meta-analysis. Anim Genet. 45:618-628.

Manunza A, Noce A, Serradilla JM, Goyache F, Martínez A, Capote J, Delgado JV, Jordana J, Muñoz E, Molina A, Landi V, Pons A, Balteanu V, Traoré A, Vidilla M, Rodriguez MS, Sànchez A, Cardoso TF, Amills M. 2016. A genome-wide perspective about the diversity and demographic history of seven Spanish goat breeds. Genet Sel Evol. 48:52.

Morel PCH, Morris ST, Kenyon PR. 2008. Effect of birth weight on survival in triplet-born lambs. Aust J Exp Agric. 48:984-987.

Nicoloso L, Bomba L, Colli L, Negrini R, Milanesi M, Mazza R, Sechi T, Frattini S, Talenti A, Coizet B, Chessa S, Marletta D, D'Andrea M, Bordonaro S, Ptak G, Carta A, Pagnacco G, Valentini A, Pilla F, Ajmone-Marsan P, Crepaldi P. 2015. Genetic diversity of Italian goat breeds assessed with a medium-density SNP chip. The Italian Goat Consortium. Genet Select Evol. 47:62.

Montaldo HH, Meza-Herrera CA. 1998. Use of molecular markers and major genes in the genetic improvement of livestock. J Biotechnol. 1:1-9.

Onogi A, Ogino A, Komatsu T, Shoji N, Shimizu K, Kurogi K, Yasumori T, Togashi K, Iwata H. 2015. Whole-genome prediction of fatty acid composition in meat of Japanese Black cattle. Anim Genet. 46:557-559.

Ortega MS, Denicol AC, Cole JB, Null DJ, Hansen PJ. 2016. Use of single nucleotide polymorphisms in candidate genes associated with daughter pregnancy rate for rediction of genetic merit for reproduction in Holstein cows. Anim Genet. 47:288-297.

Saadiah J, Johari JA, Tun-Ping Y, Nadaf J, Hifzan RM, Ernie-Muneerah MA, Khairun Hisam N, Rabiatul-Adawiyah ZA, Umi-Kalsom AB. 2014. A genome wide association study for birth weight in boer goats using a 20k single nucleotide polymorphism chip. MJVR. 5:305-307.

Sasaki S, Ibi T, Kojima T, Sugimoto Y. 2015. A genome-wide association study reveals a quantitative trait locus for days open on chromosome 2 in Japanese Black Cattle. Anim Genet. 47:102-105.

Skok DJ, Kunej T, Kovac M, Malovrh S, Potocnik K, Petric N, Zgur S, Dovc P, Horvat S. 2016. FTO gene variants are associated with growth and carcass traits in cattle. Anim Genet. 47:219-222.

Somavilla AL, Sonstegard TS, Higa RH, Rosa AN, Siqueira F, Silva LOC, Torres Junior RAA, Coutinho LL, Mudadu MA, Alencar MM, Regitano LCA. 2014. A genome-wide scan for selection signatures in Nellore cattle. Anim Genet. 45:771-781.

Tart JK, Johnson RK, Bundy JW, Ferdinand NN, McKnite AM, Wood JR, Miller PS, Rothschild MF, Spangler ML, Garrick DJ, Kachman SD, Ciobanu DC. 2013. Genome-wide prediction of age at puberty and reproductive longevity in sows. Anim Genet. 44:387-397.

Tosser-Klopp G, Bardou P, Bouchez O, Cabau C, Crooijmans R, Dong Y, Donnadieu-Tonon C, Eggen A, Heuven HCM, Jamli S, Jiken AJ, Klopp C, Lawley CT, McEwan J, Martin P, Moreno CR, Mulsant P, Nabihoudine I, Pailhoux E, Palhie 're I, Rupp R, Sarry J, Sayre BL, Tircazes A, Wang J, Wang W, Zhang W. 2014. Design and Characterization of a 52K SNP Chip for Goats. The International Goat Genome Consortium. PLoS One. 9:e86227.

Visser C, Lashmar SF, Marle-Köster EV, Poli MA, Allain D. 2016. Genetic diversity and population structure in South African, French and Argentinian Angora Goats from genomewide SNP Data. PLoS One 11:e0154353. doi: 10.1371/journal.pone.0154353. 